\title{
RANCANG BANGUN WEBSITE PENDATAAN HIMPUNAN MAHASISWA SERUYAN BERBASIS SMS BROADCAST
}

\author{
Jadiaman Parhusip ${ }^{\mathrm{a}, 1^{*}}$, Abertun S. S., ${ }^{\mathrm{b}, 2}$, M. Sabrin Safi' ${ }^{\mathrm{c}, 3}$ \\ a Jurusan Teknik Informatika FT UPR, Jl H. Timang Tunjung Nyaho \\ ${ }^{\mathrm{b}}$ Jurusan Teknik Informatika FT UPR, Jl H. Timang Tunjung Nyaho \\ ${ }^{\mathrm{c} J u r u s a n}$ Teknik Informatika FT UPR, Jl H. Timang Tunjung Nyaho \\ parhusip.jadiaman@it.upr.ac.id ${ }^{1}$; abertun.s.s@gmail.com $^{2} ;$ sabrin_077@ yahoo.com $^{3}$ \\ * corresponding author
}

ARTICLE INFO

Keywords

Waterfall

CMS

Seruyan Student Association PHP

MySQL

\section{ABSTRACT}

Seruyan student association is one of student organization in Palangka Raya. It is found that information of Seruyan students lacks enough data. It becomes a problem for the officer since the officer has to come every campus, boarding house or house to complete the data manually. It consumes too much time to collect and process the data. This designed website is hoped can help the officer collecting, managing, and informing those students' data easily. It is hoped that this website which is developed using SMS Broadcast can be very helpful in speed and quality for presenting the information. This kind of website also offer a structured storage. Besides, available information then can be accessed in an unlimited number of times and places.

This research is conducted using PHP language programme and MySQL database. The researcher also uses a methodology of software development which known as waterfall methodology (Analysis, Design, Code, Testing and Maintenance). Besides, Content Management System (CMS) is also used to manage content of the website includes command to add, change, and delete data which can be accessed from the administrator system page.

This website is tested using whitebox technique which also includes a test for visitor, member, administrator, and browser. In the other opportunity in the future, it is hoped that this website can be developed bu adding some other features such as discussion forum or chat room.

\section{PENDAHULUAN}

\subsection{Latar Belakang}

Sebagai suatu organisasi mahasiswa maka dirasa perlu untuk memanfaatkan teknologi untuk media penyampaian informasi yang berkaitan dengan Himpunan Mahasiswa Seruyan Palangka Rayaterhadapmahasiswa melalui website dinamis. Himpunan Mahasiswa Seruyan Palangka Raya mempunyai banyak kegiatan baik yang bersifat nasional maupun lokal. Himpunan Mahasiswa Seruyan ini juga melaksanakan kegiatan pengkaderan dan administrasi himpunan cukup baik. Akan tetapi karena kurangnya publikasi, maka mahasiswa yang berasal dari Seruyan belum banyak terdaftar sebagai anggota Himpunan Mahasiswa Seruyan Palangka Raya. Dengan adanya Website ini mahasiswa yang berasal dari Seruyan dengan mudah dapat mengetahui tentang seluk beluk Himpunan Mahasiswa Seruyan Palangka Raya dan mudah masuk sebagai anggota.

Oleh karena itu, melalui penelitian ini, penulis ingin merancang sebuah website dinamis untuk pendataan yang nantinya dapat dimanfaatkan sebagai media pengelolaan dan publikasi segala informasi yang terkait. 


\subsection{Perumusan Masalah}

Perumusan masalah yang diambil adalah: Bagaimana membangun websitependataan Himpunan Mahasiswa Seruyan di Palangka Raya, dengan SMS Broadcast.

\subsection{Kajian Literatur}

\subsubsection{Komponen Sistem Informasi}

Sistem informasi terdiri dari komponen-komponen yang disebut blok bangunan (building block), yang terdiri dari komponen input, komponen model, komponen output, komponen teknologi, komponen hardware, komponen software, komponen basis data, dan komponen kontrol. Semua komponen tersebut saling berinteraksi satu dengan yang lain membentuk suatu kesatuan untuk mencapai sasaran (Mahamudu,2012) [1], Lipursari (2013) [2], Anggadini [3], Warman (2012) [4]. Pengembangan Sistem Informasi telah banyak dilakukan, sebagaimana telah dikembangkan oleh Sugianor dan Yuli Nurcahyanti [5] dari Fakultas Ilmu Komputer Universitas Darwan Ali, Sampit, Kalimantan Tengah dengan judul Sistem Informasi Pendataan Penduduk Desa Ganepo Berbasis Desktop. Sistem ini dibangun dengan menggunakan tools seperti netbeans 7.0.1, sebagai bahasa pemrograman dan menggunakan database MySQL sebagai manajemen basisdatanya. Helmi Aziz [6] dari Fakultas Teknik Universitas Lampung di Bandar Lampung, 2016, telah mengembangkan Sistem Informasi Pendataan Kelahiran dan Tumbuh Kembang Bayi Berbasis Web. Sistem ini merupakan pengembangan dari proses pemantauan kesehatan bayi yang sudah ada, yakni KMS (Kartu Menuju Sehat). Agung Gondo Pramono [7] telah mengembangkan system informasi pendataan Sekolah Menengah Umum Berbasis Web di Kabupaten Lamongan. Kemudahan yang didapatkan dengan system yang dibangun tersebut adalah untuk memudahkan user dalam pencarian data-data tentang sekolah, siswa maupun guru yang ada di Kabupaten Lamongan. Moch Taufik dan Suparno Dedy Prastyo [8] dari Teknik Informatika UNISSULA telah melakukan pengembangan system informasi pendataan penduduk tingkat desa. Sistem informasi yang dibangun untuk membantu instansi pemerintah dalam melakukan pendataan penduduk dalam ruang lingkup suatu desa, khususnya dalam memproses pengajuan surat-surat kependudukan oleh setiap penduduk yang datang ke kantor kepala desa.

\subsubsection{Gammu}

Gammu adalah sebuah aplikasi cross-paltform yang digunakan untuk menjembatani/mengkomunikasikan antara database SMS Gateway atau SMS Broadcast dengan SMS devices. Aplikasi Gammu langsung memindahkannya ke dalam inbox dalam database SMS Gateway atau SMS Broadcast. Sebaliknya saat Aplikasi Pengirim SMS memasukkan SMS ke dalam outbox dalam database SMS Gateway atau SMS Broadcast, maka Gammu mengirimkannya melalui SMS devices, dan memindahkan SMS ke sentitem dalam database. SMS Gateway dengan Gammu telah banyak dilakukan, diantaranya Sri Fitriati (2009) [9]. SMS Gateway tersebut dimaksudkan untuk layanan data pendidikan siswa untuk penyediaan data pendidikan kepada siswa secara cepat, kapanpun dan dimanapun mereka membutuhkannya. Pengembangan SMS Gateway bekerjasama dengan Sekolah Menengah Atas Panca Budi Medan. Aplikasi meliputi layanan data jadwal pelajaran, data nilai semester, data absensi, serta pengiriman pengumuman dan penerimaan saran. Pemrograman dilakukan dengan menggunakan paket software XAMPP 1.6.7 yang meliputi bahasa pemrograman PHP 4.3.8 database server MySQL 5.0.51b, serta web server Apache2. Untuk SMS Hardware menggunakan handphone NOKIA 3310. Arifiano Mauluddy Gumilar [10] juga telah melakukan pengembangan Sistem Informasi Akademik Berbasis SMS Gateway pada SMAN 9 Semarang. Manfaat utama yang didapatkan yakni penyampampaian informasi nilai siswa terhadap wali murid. Muhammad Fariz Amna [11] telah mengembangkan SMS Gateway dengan Gammu yang diimplementasikan pada MtsN Pecangaan di Bawu Jepara untuk layanan data absensi, data nilai dan data jatuh tempo pembayaran SPP. M.Yanuar Ary Saputro [12] telah melakukan perancangan Sistem SMS Gateway berbasis Web dengan Gammu dan Interkoneksi di Biro Sistem Informasi Unissula Semarang. Mira Afrina dan Ali Ibrahim [13] telah melakukan pengembangan Sistem Informasi SMS 


\section{JURNAL TEKNOLOGI INFORMASI}

[E-ISSN 2656-0321]

[Vol 12. No. 1]

Jurnal Keilmutan dan Aplikasi Bidang Teknik Informatikika

[Januari 2018]

Gateway dalam meningkatkan Layanan Komunikasi Sekitar Akademika Fakultas Ilmu Komputer Unsri. Rico Andrian, dkk [14] Jurusan Ilmu Komputer UNILA dalam Jurnal Komputasi 2015 telah melakukan pengembangan Sistem Informasi Nilai Ujian Online dengan Gammu.

\subsubsection{Website Dinamis}

Dalam web dinamis, interaksi yang terjadi antara pengguna dan server sangat kompleks. Seseorangbisa mengubah konten dari halaman tertentu dengan menggunakan browser. Request (permintaan) dari pengguna dapat diproses oleh server yang kemudian ditampilkan dalam isi yang berbeda-bedamenurut alur programnya. Halaman-halaman web tersebut memiliki database. Web dinamis, memilikidata dan informasi yang berbeda-beda tergantung input apa yang disampaikan client. Dokumen yangsampai diclient akan berbeda dengan dokumen yang ada di web server.Contoh dari web dinamis adalah portal berita dan jejaring sosial. Lihat saja web tersebut, isinyasering diperbaharui (di-update) oleh pemilik atau penggunanya. Bahkan untuk jejaring sosial sangatsering di-update setiap harinya.

\section{Hasil Dan Pembahasan}

2.1 Sistem yang dikembangkan

Desain dari website "Rancang Bangun Website Pendataan Himpunan Mahasiswa Seruyan Berbasis SMS Broadcast". Mahasiswa harus mengisi form pendaftaran supaya terdaftar ke Himpunan Mahasiswa Seruyan dan itu sudah disetujui admin agar dapat mengedit riwayat pendidikan dan bisa mendownload data pribadi. 


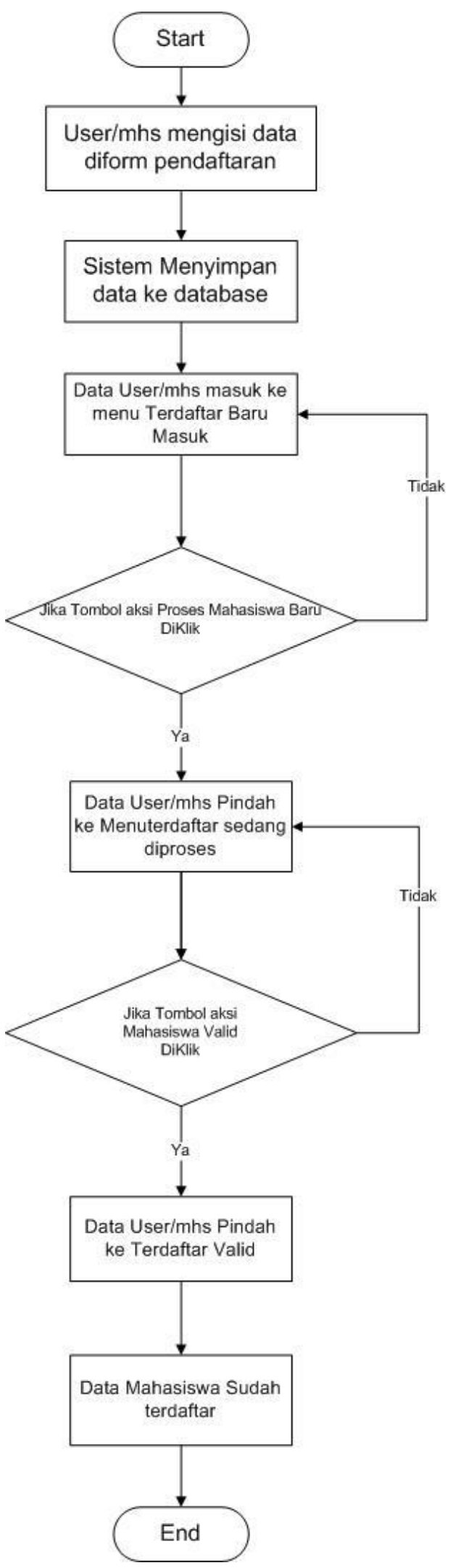

Gambar 1.Flowchart Bisnis Proses Sistem 
[E-ISSN 2656-0321]

[Vol 12. No. 1]

[Januari 2018]

Jurnal Keilmuan dan Aplikasi Bidang Teknik Informatika

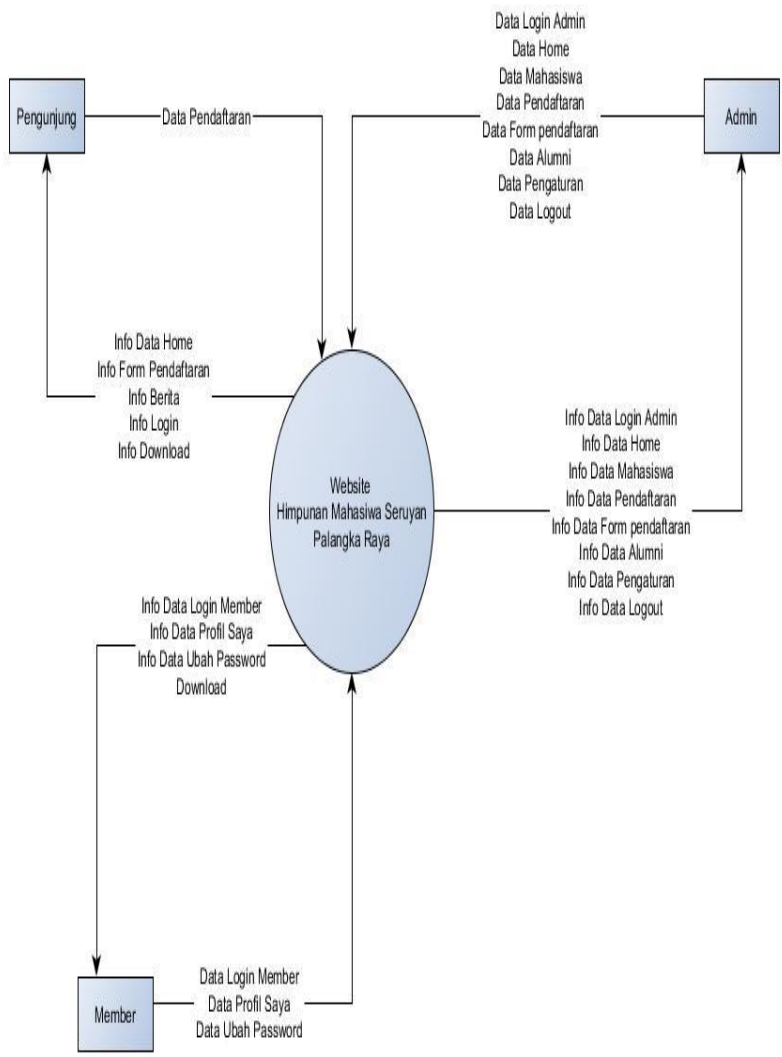

Gambar 2. Diagram Konteks

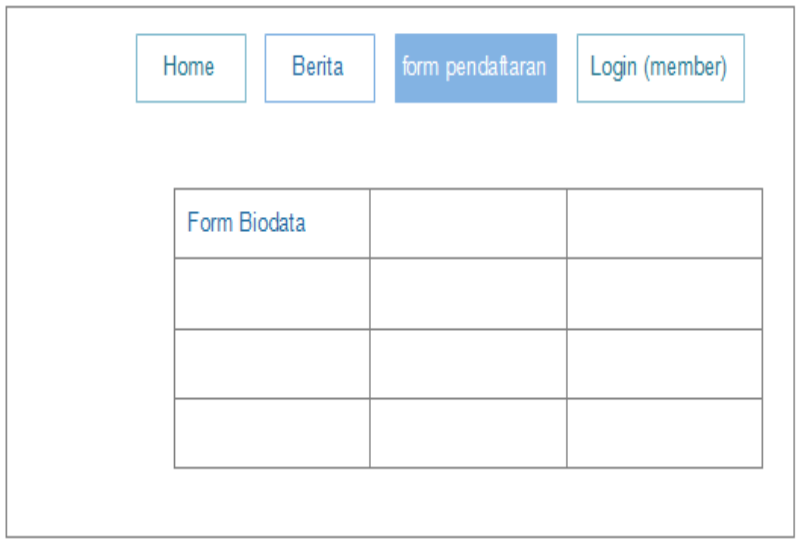

Gambar 3. Halaman Pengunjung Form Pendaftaran 


\section{JURNAL TEKNOLOGI INFORMASI}

[E-ISSN 2656-0321]

[Vol 12. No. 1]

Jurnal Keilmuan dan Aplikasi Bidang Teknik Informatilka

2.2 Halaman-halaman Website

2.2.1 Halaman Pengunjung dan login.

Pada halaman pengunjung in terdapat empat fitur diantaranya home, berita, Form pendaftaran

a. Halaman Pengun-jung Tentang Home

Pada halaman ini menampilakan data jumlah mahasiswa baru masuk, jumlah mahasiswa diproses, jumlah mahasiswa valid, data mahasiswa dan alumni serta grafiknya.

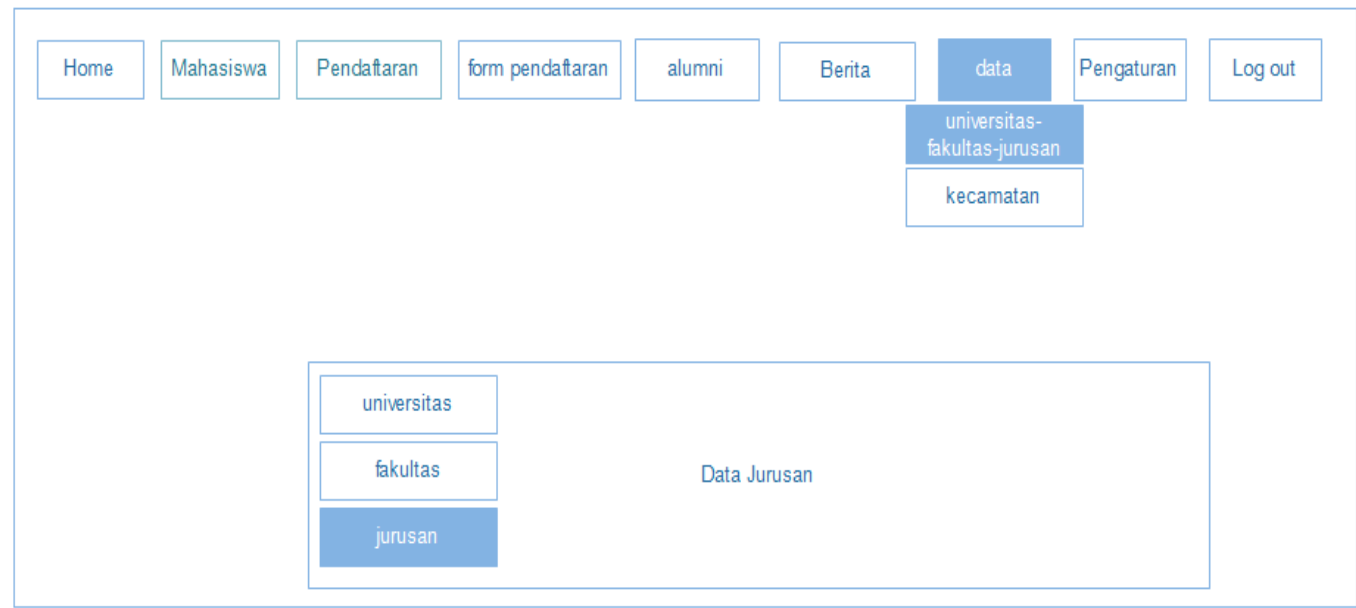

Gambar 4. Halaman Admin Data Jurusan

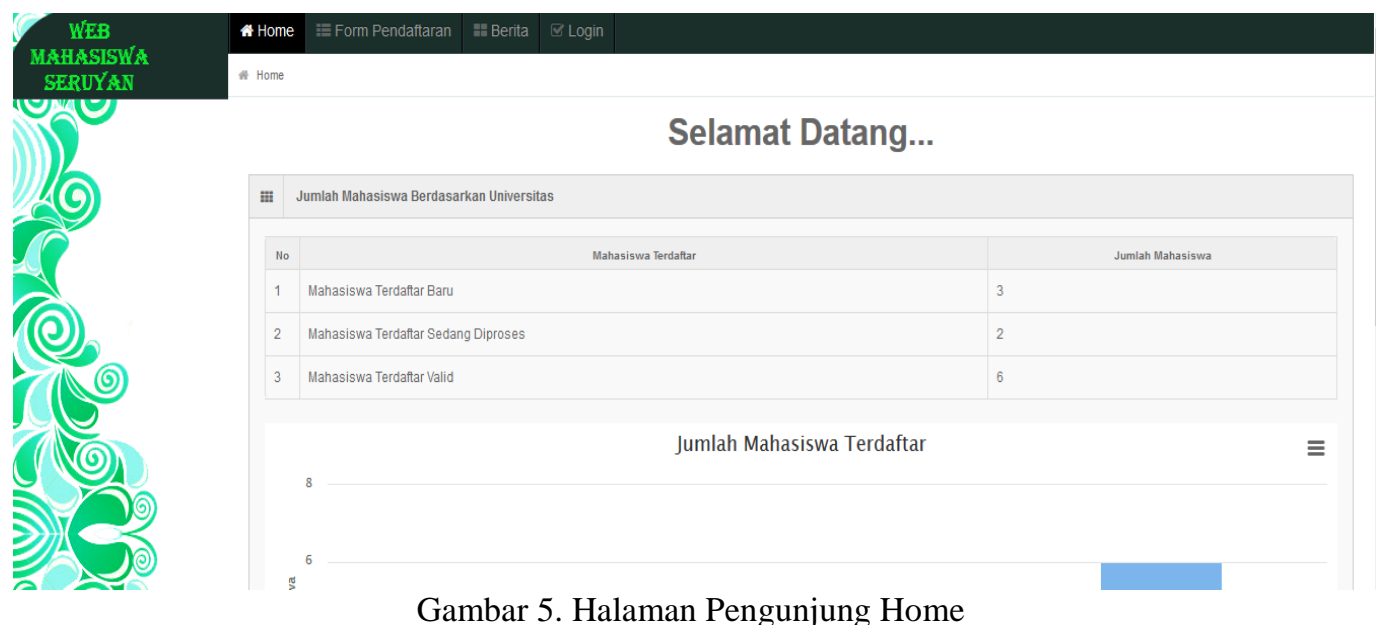

Gambar 5. Halaman Pengunjung Home 


\section{Jurnal Keilmutun dan Aplikasi Bidang Teknik Informatikika}

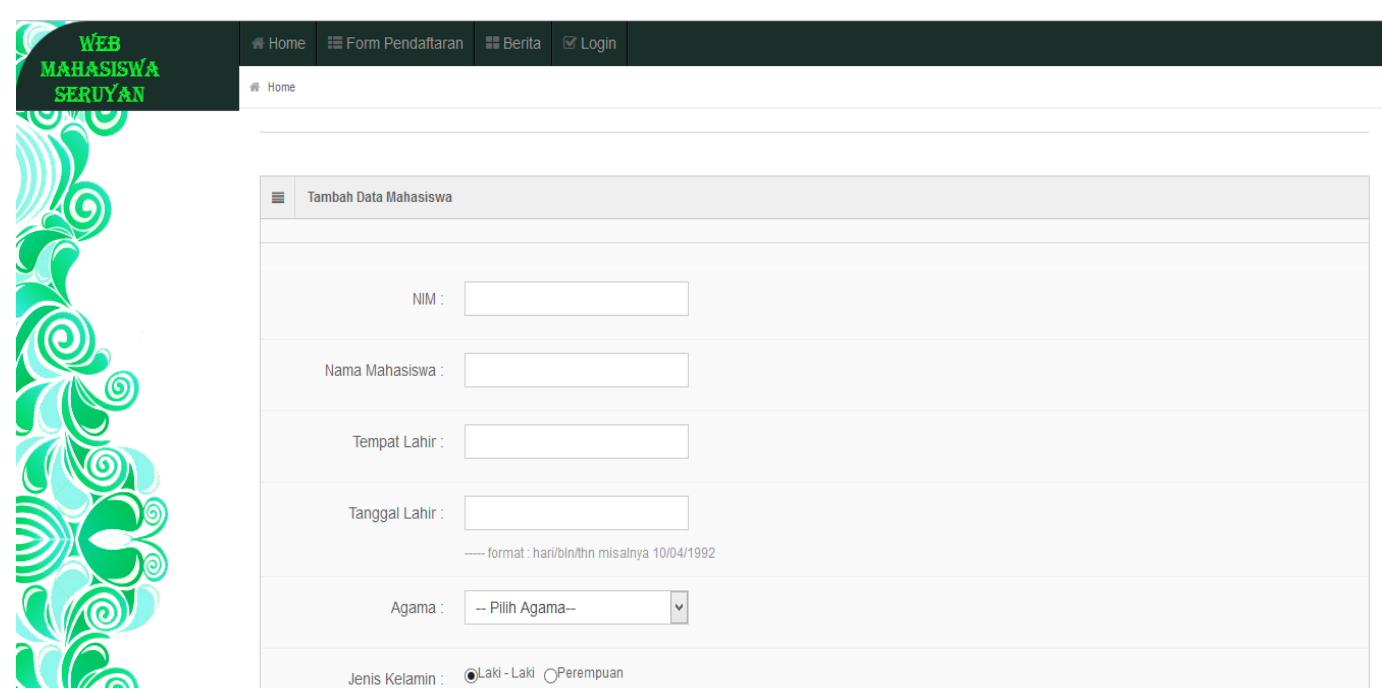

Gambar 6. Halaman Pengunjung Form Pendaftaran

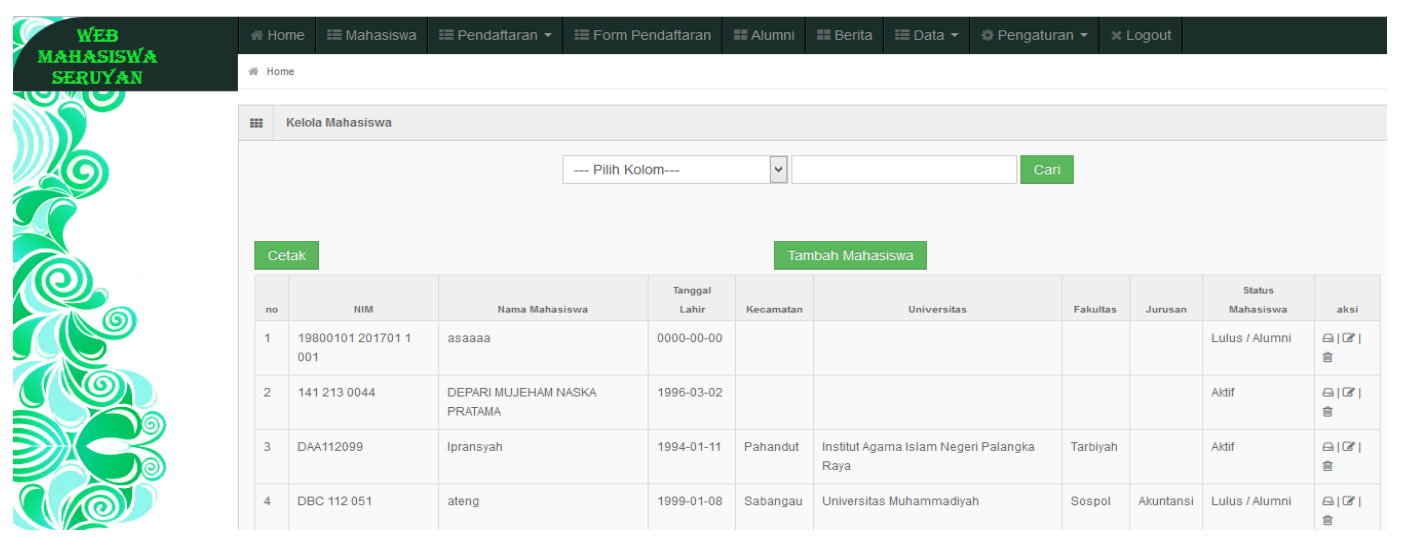

Gambar 7. Halaman admin tentang mahasiswa

\section{KESIMPULAN DAN SARAN}

\subsection{Kesimpulan}

Kesimpulan yang didapat dari judul "Rancang Bangun Website Pendataan Himpunan Mahasiswa Seruyan" adalah Website yang digunakan untuk mengoptimalkan pendataan Himpunan Mahasiswa Seruyan diPalangka Raya, agar pendataannya mudah. Yang diambil adalah :

- Untuk membangun website menggunakan operasi Windows, bahasa pemgraman PHP, database menggunakan MySql.

- Metodologi yang digunakan untuk membangun system ini adalah Model Waterfall. Model ini merupakan sebuah pendekatan terhadap pengembangan perangkat lunak yang sistematik, dengan beberapa tahapan, yaitu: System Engineering, Analysis, Design, Coding, Testing dan Maintenance.

- $\quad$ SMS Broadcast menggunakan Gammu dan Modem Cyprus.

\subsection{Saran}

Pada kesempatan mendatang diharapkan dapat mengembangkan lagi dan menambah fitur dari "Rancang Bangun Website Pendataan Himpunan Mahasiswa Seruyan" Palangka Raya ini, fiturfitur yang dapat dikembangkan dari Web ini antara lain adalah: 
1. Untuk penyempurnaan Website ini sebaiknya menggunakan forum diskusi atau chat sebagai media komunikasi antar sesama mahasiswa Seruyan Palangka Raya.

2. Memperbaiki kualitas CSS sehingga dapat memudahkan dan menarik minat pengguna dari Web ini.

\section{DAFTAR PUSTAKA}

[1] Mahamudu. Billy N., 2012. Komponen Sistem Informasi. http://apr11-si.comuf.com/komponen.php

[2] Lipursari, Anastasia. 2013. Peran Sistem Informasi Mana-jemen (SIM) Dalam Peng-ambilan Keputusan. Jurnal STIE Semarang, Vol. 5, No. 1, Edisi Februari 2013 (ISSN:2252-7826) https://media.neliti.com

[3] Anggadini, Sri Dewi. Tanpa Tahun. Analisis Sistem Informasi Manajemen Ber-basis Komputer Dalam Proses Pengambilan Kepu-tusan. Majalah Ilmiah UNIKOM Vol. 11 No. 2 https://jurnal.unikom.ac.id

[4] Warman, Indra. 2012. Sistem Informasi Alumni ITP Menggunakan PHP dan MySQL.https://ejournal.itp.ac.id

[5] Christianti, Meliana,dan Bimo Seto Prakoso. 2015. Analisisdan Perancangan Sistem Informasi Akademik dengan Studi Kasus Pada Sekolah Menengah Atas Terpadu (SMAT) Krida Nusantara. Jurnal Sistem Informasi 3 (1), 2015. https://maranatha.edu

[6] Helmi, Aziz. 2016. Sistem Informasi Pendataan Kela-hiran dan Tumbuh Kem-bang Bayi Berbasis Web (Skripsi). Fakultas Teknik Universitas Lampung, Bandar Lampung. https://digilib.unila.ac.id

[7] Agung Gondo Pramono. Tanpa Tahun. Sistem Informasi Pendataan Sekolah Mene-ngah Umum (SMU) Berbasis Web Di Kabupaten Lamongan. http:// ejournal.narotama.ac.id

[8] Prasetyo, Dedy dan Moch Taufik. 2009. Pengembangan Sis-tem Informasi Penda-taan Penduduk Tingkat Desa. Teknik Informatika UNIS-SULA. ISBN 978-602-95235-0-8 Proceedings Seminar Nasional Tekno-logi Industri (SNTI) 2009 Universitas Sultan Agung Semarang https://eriset.unimus.ac.id

[9] Fitriati, Sri. 2010. Perancangan Sistem Informasi Berbasis SMS Dan Implementasinya Di Sekolah Menengah Atas Panca Budi Medan. https://repository.usu.ac.id

[10] Ariviano Mauluddy Gumilar. 2014. Sistem Informasi Akademik Berbasis Gate-way Pada SMA N 9 Semarang. Program StudiSistem Informasi Fakultas Ilmu Komputer Universitas Dian Nuswantoro, Semarang. https://eprint.dinus.ac.id

[11] Amna, Muhammad Fariz. Sistem Informasi Sekolah Ber-basis SMS Gateway De-ngan Gammu Pada MtsN Pecangaan di Bawu Jepara. Program Studi Teknik Informatika Fak. Ilmu Komputer Univ. Dian Nuswantoro Semarang http://eprints.udinus.ac.id

[12] Saputro, M.Yanuar Ari. 2011. Perancangan Sistem SMS GatewayBerbasis Web dengan Gammu dan Interkoneksi di Biro Sistem Informasi Unissula Sema-rang. Jurusan Teknik Elek-tro Fakultas Teknik Universitas Diponegoro http://elektro.undip.ac.id

[13] Afrina, Mira dan Ali Ibrahim. 2015. Pengembangan Sis-tem Informasi SMS Gate-way Dalam Meningkatkan Layanan Komunikasi Seki-tar Akademik Fakultas Ilmu Komputer UNSRI. Jurnal Sistem Informasi Fasilkom Universitas Sri-wijaya. Jurnal Sistem Informasi (JSI), VOL. 7.No. 2, Oktober 2015. http://ejournal.unsri.ac.id/index.php/jsi/index 
[14] Adrian, Nico, Didik Kurniawan, RA.Dina Nia Pratiwi. 2015. Pengembangan Sis-tem Informasi Nilai Ujian Online Dengan Gaтmu. Jurusan Ilmu Komputer FMIPA Unila. Ilmu Komputer Unila Publis-hing Network,Vol. 3, No. 1, 2015. http://digilib.unila.ac.id 